\title{
Epoxy and epoxy novolac adhesive binders for structural reinforcement systems of building structures
}

\author{
Irina Starovoitova ${ }^{1[0000-0002-4004-7423]^{*}}$, and Rustem Nizamiev ${ }^{\text {[0000-0002-6073-065X] }}$ \\ ${ }^{1} \mathrm{OOO}$ «Scientific and production company «Recon», 420043 Kazan, Russia \\ ${ }^{2}$ Kazan National Research Technical University named after A.N. Tupolev, 420011 Kazan, Russia
}

\begin{abstract}
Today, along with the conventional materials and technologies for reinforcement of building structures, structural reinforcement systems based on polymer composites are on the rise. A structural reinforcement system consists of reinforcing filler (normally, carbon fiber fabric or cloth) and adhesive binder. This paper investigated the modification of epoxy nobake adhesive binders to provide a higher thermal resistance and mechanical strength. The influence of epoxy novolac resins on the processing and physical mechanical properties of adhesives, thermal resistance is studied. It is found that the substitution of $20-40 \%$ of epoxy resin for epoxy novolac resin in the binder increases tensile strength by $40-50 \%$, flexural modulus by $20 \%$, reduces tensile strain, and increases glass transition temperature. From the processing point of view, it is more reasonable to use liquid epoxy novolac resins with a functionality of $f=2.5$ than semisolid resins with a functionality of $f=3.6$.
\end{abstract}

Keywords. Structural reinforcement systems, epoxy adhesive binders, modification, epoxy novolac resin, tensile strength, flexural modulus, glass transition temperature.

\section{Introduction}

The need for reinforcement of load-bearing building structures made of concrete, reinforced concrete, brickwork, and steel arises from a variety of reasons, including:

- ageing and failure of materials during their long term operation when exposed to mechanical loads and environmental factors (positive and negative temperatures, UV radiation, aggressive media, etc.) followed by a decrease in bearing capacity;

- assurance of reliability and bearing capacity of structures in cases of design and construction in high seismic hazard zones, under extreme loads; higher intermaitenance periods; higher loads due to changes in a structural scheme of elements of a facility; correction of various defects caused by design, transportation, installation of structures, etc.

In the past, the main reinforcement method for building structures was to increase their section (by attaching additional elements to them, lessening the load on structures, installing backup elements), which was high energy and labour intensive. The conventional and

${ }^{*}$ Corresponding author: irina-starovoitova@yandex.ru 
effective (in regard to an increase in bearing capacity) reinforcement methods also include attachment of steel plates in a tension area of reinforced elements. Among the disadvantages of this method are higher corrosion rate due to the external position of steel plates; failure of adhesion bond between plates and concrete due to a significant own weight, which can result in separation of plates during the operation; use of large-size equipment and time-consuming work; inability to strengthen bent elements and surfaces. In addition, the existing conventional reinforcement methods are relatively expensive, labour intensive, and frequently require decommissioning of a construction during repair.

Today, along with the conventional materials and technologies for reinforcement of structures, the production and use of structural reinforcement systems (SRS) made of polymer composite materials are on the rise. According to GOST 33369-2015, SRSs are classified as follows:

- by type of reinforcing filler: fiberglass composite, carbon composite, and combined composite;

- by material of thermosetting polymer matrix: vinyl ester thermosets, epoxy thermosets;

- by manufacturing method: on the site of strengthening and rehabilitation of a building structure, under factory conditions.

Carbon reinforcing fillers (cloth, fabrics, tapes) are most widely used for SRSs. They have a higher flexural modulus than other fiber types (Table 1). Basalt fibers are also noteworthy for their properties and maximum possible operating temperature (up to $700{ }^{\circ} \mathrm{C}$ ). Besides, glass and basalt fibers are much cheaper than carbon and aramid fibers.

Table 1. Physical mechanical properties of reinforcing fillers.

\begin{tabular}{|c|c|c|c|c|}
\hline No. & Fiber & Density $\left(\mathrm{g} / \mathrm{cm}^{3}\right)$ & Tensile strength $(\mathrm{GPa})$ & Flexural modulus $(\mathrm{GPa})$ \\
\hline 1 & Carbon & $1.6-2.0$ & $3.5-7.0$ & $230-700$ \\
\hline 2 & Glass & $2.2-2.8$ & $1.4-4.3$ & $50-90$ \\
\hline 3 & Basalt & $2.6-3.0$ & $2.5-4.0$ & $80-90$ \\
\hline 4 & Aramid & $1.4-1.5$ & $2.9-3.4$ & $70-140$ \\
\hline
\end{tabular}

Special adhesive compounds ensure the combined action of high-strength reinforcing fillers and material of a repaired structure (normally, concrete or reinforced concrete). Epoxy compounds became widespread as adhesives for SRS, which is due to their processability, high strength properties, and good adhesion to reinforcing fillers and materials of reinforced structures. For the best possible adhesion, reinforcing fillers (cloth, fabrics, tapes) treated with epoxy-based systems during their production should be selected. Fillers with paraffin oil cannot be treated with epoxy compounds uniformly (due to their bad compatibility and wettability), and they reduce interfacial adhesion and strength properties of a reinforcement system.

The majority of publications about study, development, and application of compositebased reinforcement systems are associated with testing of reinforced products and structure elements, refinement of calculation methods and practical experience of their implementation [1-17]. Meanwhile, the Russian market is dominated by imported epoxy compounds, and there are hardly any publications about development and study of epoxy adhesives for SRS.

Scientific and Production Company «Recon» along with Kazan State University of Architecture and Engineering developed epoxy no-bake binders RecARM [18-20] to be used together with carbon fiber fabrics for SRS. The addition of dispersion of multi-walled carbon nanotubes to the binder (0.0025-0.01 weight fractions per 100 weight fractions of epoxy resin) improved adhesion properties, tensile and flexural strength [19].

The objective of this paper is to study and develop methods for modifying epoxy adhesive binders RecARM to increase thermal resistance and mechanical strength. 


\section{Materials and methods}

For the purposes of increasing a set of properties of adhesive binders, adhesive compound modified with epoxy novolac resins DEN-425 and DEN-438 (from Olin Corporation) at the ratio of from 10:90 to 50:50 against the standard epoxy-diane resin was studied. The properties of the used resins are shown in Table 2.

Table 2. Structure and properties of the used epoxy resins.

\begin{tabular}{|c|c|c|c|}
\hline \multirow[b]{2}{*}{ Parameter } & \multicolumn{3}{|c|}{ Parameter value for resin: } \\
\hline & $\begin{array}{c}\text { NPEL-128S/DER-331 } \\
\text { (Nan Ya Plastics Corporation/ } \\
\text { Olin Corporation) }\end{array}$ & $\begin{array}{l}\text { DEN-425 } \\
\text { (Olin } \\
\text { Corporation) } \\
\end{array}$ & $\begin{array}{l}\text { DEN-438 } \\
\text { (Olin } \\
\text { Corporation) } \\
\end{array}$ \\
\hline Type of resin & $\begin{array}{l}\text { Epoxy-diane resin is a product of } \\
\text { condensation of epichlorohydrin and } \\
\text { bisphenol A }\end{array}$ & \multicolumn{2}{|c|}{$\begin{array}{l}\text { Epoxy novolac resin is a product } \\
\text { of condensation of } \\
\text { epichlorohydrin and phenol- } \\
\text { formaldehyde novolac } \\
\end{array}$} \\
\hline \multicolumn{4}{|l|}{ Structure } \\
\hline Condition & Liquid & Liquid & Semisolid \\
\hline $\begin{array}{l}\text { Epoxy equivalent } \\
\text { weight (g/eq) }\end{array}$ & 205-225/182-192 & $169-179$ & $176-181$ \\
\hline Viscosity $(\mathrm{mPa} \times \mathrm{s})$ & $\begin{array}{c}19000-24000 / 11000-14000 \\
\left(\text { at }+25^{\circ} \mathrm{C}\right)\end{array}$ & $\begin{array}{l}9500-12500 \\
\left(\text { at }+25^{\circ} \mathrm{C}\right)\end{array}$ & $\begin{array}{c}22500-50000 \\
\left(\text { at }+52{ }^{\circ} \mathrm{C}\right)\end{array}$ \\
\hline Density $\left(\mathrm{g} / \mathrm{cm}^{3}\right)$ & 1.16 & 1.20 & 1.22 \\
\hline
\end{tabular}

Epoxy novolac resin combines thermal resistance of a phenolic chain with reactivity of epoxy groups. Multipurpose epoxy novolac resins (Table 2 ) have a high density and provide more stable cross-linked structure after hardening, which increases chemical and thermal resistance of a material [21-23]. Functionality of the selected epoxy novolac resins is as follows: $\mathrm{f}=2.5$ (DEN-425) and $\mathrm{f}=3.6(\mathrm{DEN}-438)$.

There are requirements for processability (pot life, viscosity, hardening ability at temperatures from $+10 \div+15{ }^{\circ} \mathrm{C}$ to $+30 \div 35{ }^{\circ} \mathrm{C}$ ) and performance properties (tensile and compressive strength, flexural modulus, shearing and peeling strength, glass transition temperature, thermal expansion coefficient, and shrinkage) of adhesive binders for composite-based SRSs.

Processing properties, tensile strength and flexural modulus, and glass transition temperature were chosen as test parameters at the first stage of experimental studies and optimization of the compositions of epoxy and epoxy novolac adhesive binders.

The viscosity of the binders and final adhesive compounds was measured with a Brookfield viscometer, the strength and flexural modulus - with tensile testing machine 5882 from Instron, glass transition temperature - with dynamic mechanical analyzer Q800 DMA from TA INSTRUMENTS.

The reference compound was adhesive binder RecARM-B based on epoxy resin with modifying additives and mixed amine hardener. The hardener was a mixture of aromatic amines.

The binder of the adhesive compound was prepared using the following procedure:

1. Mixing of epoxy and epoxy novolac resin using the laboratory dissolver at a mixing rate of minimum 800-1000 rpm for about 40-50 minutes at a temperature of $\mathrm{t}=+(20 \pm 2){ }^{\circ} \mathrm{C}$. 
For semisolid epoxy novolac resin DEN-438, mixing was performed at a temperature of $\mathrm{t}=$ $+(50 \pm 5){ }^{\circ} \mathrm{C}$;

2. Sequential addition of reactive diluent and plasticizer to the mixture of resins with stirring for minimum 30 minutes at each stage;

3. Addition of rheology agents (foam suppressant, wetting agent) and stirring for 10-20 minutes.

\section{Results and discussion}

The processing properties of the adhesives are given in Table 3 .

Table 3. Processing properties of the adhesives based on the mixtures of epoxy-diane and epoxy novolac resins.

\begin{tabular}{|c|c|c|c|}
\hline \multirow[b]{2}{*}{$\begin{array}{c}\text { Sample } \\
\text { No. }\end{array}$} & \multirow[b]{2}{*}{ Type and ratio of resins in binder } & \multicolumn{2}{|c|}{ Processing properties } \\
\hline & & $\begin{array}{l}\text { Viscosity of binder } \\
\text { at } 25^{\circ} \mathrm{C}(\mathrm{mPa} \times \mathrm{s})\end{array}$ & Pot life at $20^{\circ} \mathrm{C}(\mathrm{min})$ \\
\hline 1 & $\begin{array}{l}\text { Reference compound RecARM-B } \\
(N P E L-128 S=100)\end{array}$ & $3500-4000$ & $90-110$ \\
\hline 2 & NPEL-128S/DEN-425 = 90:10 & $5000-5500$ & $120-140$ \\
\hline 3 & NPEL-128S/DEN-425 = 80:20 & $4500-5000$ & $110-120$ \\
\hline 4 & NPEL-128S/DEN-425 = 70:30 & $4000-4500$ & $90-100$ \\
\hline 5 & NPEL-128S/DEN-425 = 60:40 & $2500-3000$ & $90-100$ \\
\hline 6 & NPEL-128S/DEN-425 = 50:50 & $2000-2400$ & $80-90$ \\
\hline 7 & DEN-425 $=100$ & $1800-2200$ & $60-70$ \\
\hline 8 & DER-331/DEN-425 = 90:10 & $5000-5500$ & $70-80$ \\
\hline 9 & DER-331/DEN-425 = 80:20 & $6000-7000$ & $70-80$ \\
\hline
\end{tabular}

According to Table 3, the addition of liquid epoxy novolac resin DEN-425 to the binder changes the viscosity of the system: when 10-20 weight fractions of epoxy resin is substituted for epoxy novolac resin the viscosity increases insignificantly; when the content of epoxy novolac resin is increased to 40-50 weight fractions the viscosity decreases by 1.5-2 times. When semisolid epoxy novolac resin DEN-438 (10-20 weight fractions) is added to the binder the viscosity increases significantly. It explains why less viscous epoxy-diane resin DER-331 is used when semisolid resin DEN-438 is added to the compound.

It is important to note that when the hardener is added to the binder and mixed, the viscosity of the final adhesive compound is lower that the viscosity of the binder (from 1500 to $5000-6000 \mathrm{mPa} \times \mathrm{s})$.

The pot life varies from 50-60 minutes to 120 minutes depending on the ratio of epoxy and epoxy novolac resins in the composition.

The tensile strength and flexural modulus of the hardened compounds were studied, their glass transition temperature was determined.

Fig. 1 shows the tensile strength of the adhesive compounds based on the mixtures of epoxy resin NPEL-128S and epoxy novolac resin DEN-425 at test temperatures of $t=+22$; $+40{ }^{\circ} \mathrm{C}$. Partial substitution of epoxy-diane resin (20-40\%) for epoxy novolac resin DEN425 increases the tensile strength from $45 \mathrm{MPa}$ to $62-68 \mathrm{MPa}$. With a higher content of epoxy novolac resin DEN-425, the degree of tensile strength retention at $\mathrm{t}=+40{ }^{\circ} \mathrm{C}$ increases from 45 to $75-80 \%$.

The tensile strength of the adhesive compounds based on epoxy resin DER-331 and semisolid epoxy novolac resin DEN-438 is 65 and $70 \mathrm{MPa}$ with a content of DEN-438 of 10 and 20 weight fractions, respectively. The degree of strength retention is $70 \%$. 


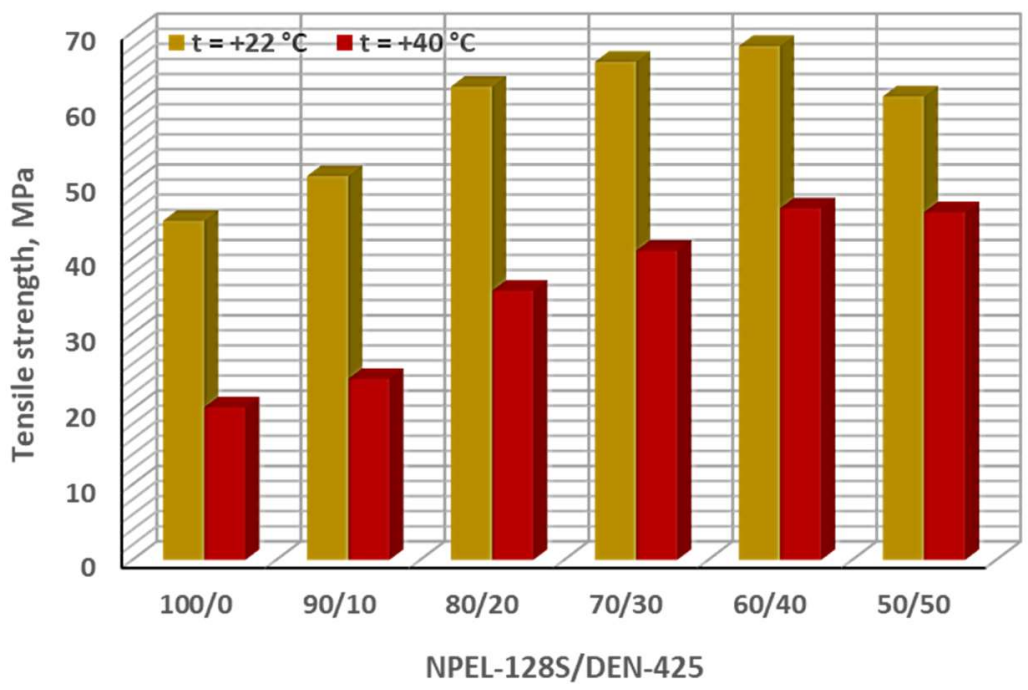

Fig. 1. Tensile strength of the adhesive compounds based on the mixtures of resins NPEL-128S and DEN -425 at +22 and $+40{ }^{\circ} \mathrm{C}$.

The results of the elevated-temperature mechanical tests correlate to the glass transition temperatures of the hardened adhesives, which were determined by dynamic mechanical analysis (DMA).

According to the DMA data (Fig. 2), the glass transition temperature of the hardened adhesive increases from $50{ }^{\circ} \mathrm{C}$ to $+55 \div+59{ }^{\circ} \mathrm{C}$ when epoxy novolac resin DEN-425 is added to the compound (substitution of $20-50 \%$ of NPEL-128S resin in the composition). The glass transition temperature increases by $5-7{ }^{\circ} \mathrm{C}$ : from $47{ }^{\circ} \mathrm{C}$ to $52-54{ }^{\circ} \mathrm{C}$ when $\mathrm{DEN}-438$ is added (substitution of $10-20 \%$ of DER-331 resin). The difference between glass transition temperatures of the reference samples $\left(47^{\circ} \mathrm{C}\right.$ and $\left.50^{\circ} \mathrm{C}\right)$ results from the use of epoxy resins which have slightly different molecular mass and epoxy equivalent weight.

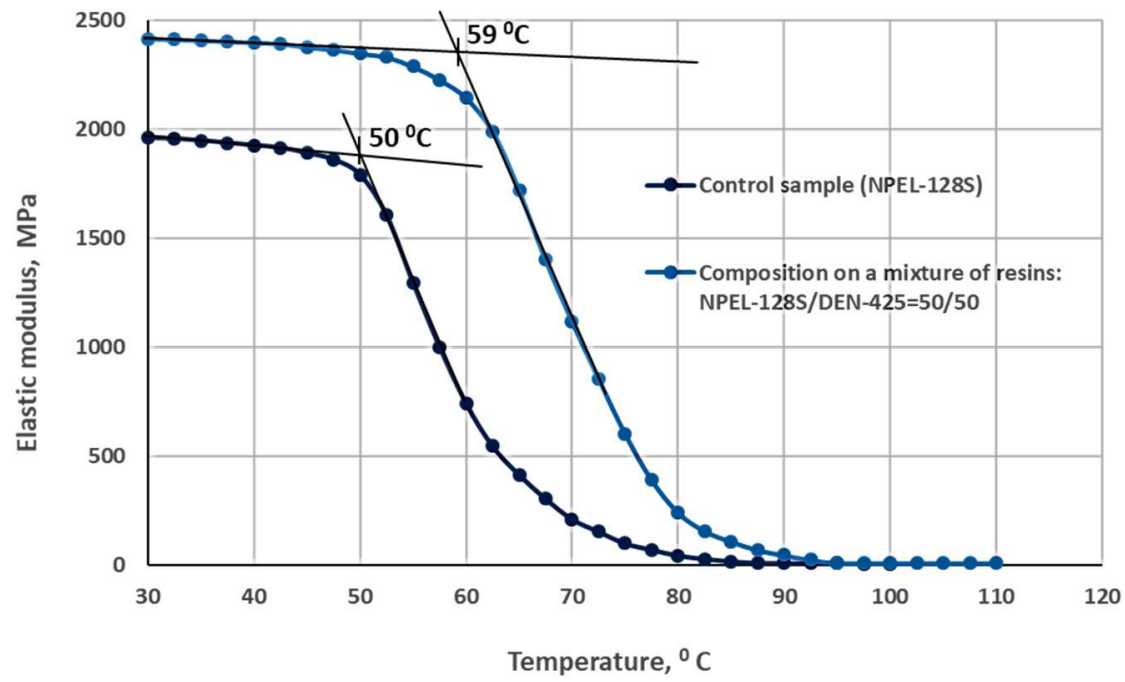

Fig. 2. Dynamic mechanical analysis of the hardened adhesives:

- control sample (NPEL-128S/DEN-425 = 100/0); - NPEL-128S/DEN-425 = 50/50. 
Table 4 shows the flexural modulus and tensile strain of the adhesive compounds based on the mixture of resins NPEL-128S and DEN-425. The tests were performed at $\mathrm{t}=+22{ }^{\circ} \mathrm{C}$.

Table 4. Tensile strength, flexural modulus and tensile strain.

\begin{tabular}{|c|c|c|c|c|}
\hline \multirow{2}{*}{$\begin{array}{c}\text { Sample } \\
\text { No. }\end{array}$} & \multirow{2}{*}{$\begin{array}{c}\text { Ratio of resins NPEL- } \\
\text { 128S/DEN-425 in the binder }\end{array}$} & $\begin{array}{c}\text { Tensile strength } \\
(\mathrm{MPa})\end{array}$ & $\begin{array}{c}\text { Flexural modulus } \\
(\mathrm{GPa})\end{array}$ & $\begin{array}{c}\text { Tensile } \\
\text { strain (\%) }\end{array}$ \\
\hline 1 & Reference compound (100:0) & 45 & 5.6 & 1.7 \\
\hline 2 & $90: 10$ & 50.9 & 5.8 & 1.5 \\
\hline 3 & $80: 20$ & 62.8 & 6.1 & 1.3 \\
\hline 4 & $70: 30$ & 66.1 & 6.6 & 1.2 \\
\hline 5 & $60: 40$ & 68.2 & 7.0 & 1.0 \\
\hline 6 & $50: 50$ & 61.5 & 6.8 & 0.9 \\
\hline
\end{tabular}

The partial substitution of epoxy-diane resin for liquid epoxy novolac resin DEN-425 in the binder of the adhesive compound provides a higher flexural modulus and lower tensile strain as a result of a higher hardness of the adhesive due to the formation of a denser structure with a lot of cross-links after hardening.

\section{Conclusion}

The use of mixtures of epoxy-diane and epoxy novolac resins in adhesive binders for SRSs has enough potential from technical and commercial point of view. Substitution of $20-40 \%$ of epoxy resin for epoxy novolac resin in the binder increases tensile strength by $40-50 \%$, flexural modulus by $20 \%$, reduces tensile strain, and increases glass transition temperature.

When 50 weight fractions of liquid epoxy novolac resin DEN-425 $(f=2.5)$ are added to the compound (per 50 weight fractions of epoxy resin), the processability of the adhesive compound shows little change, when semisolid epoxy novolac resin DEN-438 $(f=3.6)$ is added to the compound, the viscosity of the binder increases twofold even with $20 \%$ of epoxy resin replaced. Maximum tensile strength is $65-70 \mathrm{MPa}$ with $10-20 \%$ of epoxy resin replaced by DEN-438 resin, which corresponds to the strength of the hardened adhesive with $30-40 \%$ of epoxy resin replaced by DEN-425 resin. In general, it is more reasonable to use liquid epoxy novolac resins than semisolid resins from the processing point of view. The highest glass transition temperature of the adhesive corresponds to maximum content of epoxy novolac resin in the compound, which is due to a higher cross-link density after hardening as a result of a higher functionality of the proportion of resin present.

Therefore, the effectiveness of epoxy novolac resins in the adhesive binders for SRSs and the formation of a set of higher performance properties have been proved.

Further studies may focus on the investigation of adhesion properties of adhesive compounds, rupture life and durability, as well as performance evaluation in reinforcement systems.

\section{References}

1. M.Z. Naser, R.A. Hawileh, J.A. Abdalla. Fiber-reinforced polymer composites in strengthening reinforced concrete structures: A critical review, Engineering Structures 198, 1 November, 109542 (2019). DOI: 10.1016/j.engstruct.2019.109542.

2. S.J.E. Dias, J.R.M. Silva, J.A.O. Barros. Flexural and shear strengthening of reinforced concrete beams with a hybrid CFRP solution, Composite Structures 256, 113004 (2021). DOI: 10.1016/j.compstruct.2020.113004. 
3. Ö.S.Türkmen, S.N.M.Wijte, J.Vaculik, B.T.De Vries, J.M.Ingham. High-speed pullout behavior of deep-mounted CFRP strips bonded with a flexible adhesive to clay brick masonry, Structures 28, 1153-1172 (2020). DOI: 10.1016/j.istruc.2020.09.026.

4. C. Pellegrino, G. Giacomin, R.A. Perlo. Experimental investigation on existing precast prc elements strengthened with cementitious composites, Alternativas 17 3, 65-69 (2016). DOI: 10.23878/alternativas.v17i3.214.

5. N. Nikoloutsopoulos, D. Passa, S. Gavela, A. Sotiropoulou. Comparison of shear strengthening techniques of reinforced concrete beams with carbon fibre reinforced polymers (CFRPs), Procedia Structural Integrity 10, 141-147 (2018). DOI: 10.1016/j.prostr.2018.09.021.

6. V. Gribniak, Ng Pui-Lam, V. Tamulenas, I. Misiunaite, A. Norkus, A. Šapalas. Strengthening of Fibre Reinforced Concrete Elements: Synergy of the Fibres and External Sheet, Sustainability (MDPI) 11, 1-13 (2019). DOI: 10.3390/su11164456.

7. Wissam D. Salman, Ahmed Abdullah Mansor. Fibrous geopolymer paste composites for near-surface-mounted strengthening of reinforced concrete beams in flexure, Case Studies in Construction Materials 14, e00529 (2021). DOI: 10.1016/j.cscm.2021.e00529.

8. Shraddha B. Tibhe, Vijaykumar R. Rathi. Comparative Experimental Study on Torsional Behavior of RC Beam Using CFRP and GFRP Fabric Wrapping, Procedia Technology 24, 140-147 (2016). DOI: 10.1016/j.protcy.2016.05.020.

9. Julian Carrillo, William Valencia-Mina, Edén Bojórquez. Compressive performance of square and low-strength concrete columns retrofitted with externally-bonded CFRP, Materials Today Communications, Volume 23, 100874 (2020). DOI: 10.1016/j.mtcomm.2019.100874.

10. Amir Shomali, Davood Mostofinejad, Mohammad Reza Esfahani. Effective strain of CFRP in RC beams strengthened in shear with NSM reinforcements, Structures 23, 635-645 (2020). DOI: 10.1016/j.istruc.2019.10.020.

11. Liu Jin, Xuan-ang Jiang, Hai Xia, Fengjuan Chen, Xiuli Du. Size effect in shear failure of lightweight concrete beams wrapped with CFRP without stirrups: Influence of fiber ratio, Composites Part B: Engineering 199, 108257 (2020). DOI: 10.1016/j.compositesb.2020.108257.

12. Mário R.F. Coelhoa, José M. Sena-Cruza, Luís A.C. Neves. A review on the bond behavior of FRP NSM systems in concrete, Construction and Building Materials 93, 1157-1169 (2015). DOI: 10.1016/j.conbuildmat.2015.05.010.

13. A. Chalot, L. Michel, E. Ferrier. Experimental study of external bonded CFRP-concrete interface under low cycle fatigue loading, Composites Part B: Engineering 177, 107255 (2019). DOI: 10.1016/j.compositesb.2019.107255.

14. K. Sakthimurugan, K. Baskar. Experimental investigation on rcc external beam-column joints retrofitted with basalt textile fabric under static loading, Composite Structures 268 , 114001 (2021). DOI: 10.1016/j.compstruct.2021.114001.

15. Weina Meng, Kamal Henri Khayat, Yi Bao. Flexural behaviors of fiber-reinforced polymer fabric reinforced ultra-high-performance concrete panels, Cement and Concrete Composites 93, 43-53 (2018). DOI: 10.1016/j.cemconcomp.2018.06.012.

16. Emanuela Speranzini. Effectiveness of new generation fabrics for reinforcement of nontensile resistant materials, Composite Structures 227, 111315 (2019). DOI: 10.1016/j.compstruct.2019.111315.

17. I.A. Starovoitova, A.N. Semenov, Ye.S. Zykova, V.G. Khozin, A.M. Suleymanov. Modified glue binders for systems of external reinforcement of building structures. Part 1. Requirements for glues, technological characteristics, Stroitel'nye Materialy 11, 50-54 (In Russian) (2017).

18. I.A. Starovoitova, A.R. Shakirov, E.S. Zykova, A.N. Semenov, A.M. Suleimanov. Research of physical and mechanical characteristics of modified adhesive binders for 
structural reinforcement systems of building structures, Stroitel'nye Materialy 1-2, 98-104 (2021). DOI: 10.31659/0585-430X-2021-788-1-2-00-00.

19. A.M. Suleimanov, A.R. Shakirov, A.F. Agliullina, I.A. Starovoitova. The research of short-term and long-term strength of adhesives bond joint for the external reinforcement of building structures, Izvestija KGASU 4 (46), 309-318 (In Russian) (2018).

20. Ayman M. Atta, M.I. Abdou, Abdel-Atif A. Elsayed, Mohamed E. Ragab. New bisphenol novolac epoxy resins for marine primer steel coating applications, Progress in Organic Coatings 63, Iss. 4, 372-376 (2008). DOI: 10.1016/j.porgcoat.2008.06.013.

21. Amin Abdollahi, Hossein Roghani-Mamaqani, Mehdi Salami-Kalajahi, Alireza Mousavi, Bahareh Razavi, Sina Shahi. Preparation of organic-inorganic hybrid nanocomposites from chemically modified epoxy and novolac resins and silica-attached carbon nanotubes by sol-gel process: Investigation of thermal degradation and stability, Progress in Organic Coatings 117, 154-165 (2018). DOI: 10.1016/j.porgcoat.2018.01.001.

22. Pyeong-Su Shin, Zuo-Jia Wang, Dong-Jun Kwon, Jin-Yeong Choi, II. Sung, Dal-Saem Jin, Suk-Won Kang, Jeong-Cheol Kim, K. Lawrence De Vries, Joung-Man Park. Optimum mixing ratio of epoxy for glass fiber reinforced composites with high thermal stability, Composites Part B: Engineering 79, 132-137 (2015). DOI: 10.1016/j.compositesb.2015.04.032. 